\title{
The regulation and function of CD20: an "enigma" of B-cell biology and targeted therapy
}

\author{
Gabriela Pavlasova ${ }^{1,2}$ and Marek Mraz ${ }^{1,2}$ \\ ${ }^{1}$ Central European Institute of Technology, Masaryk University, Brno and ${ }^{2}$ Department of \\ Internal Medicine, Hematology and Oncology, University Hospital Brno and Faculty of \\ Medicine, Masaryk University, Brno, Czech Republic
}

Haematologica 2020

Volume 105(6):1494-1506

\section{Correspondence: \\ MAREK MRAZ \\ marek.mraz@email.cz \\ Received: Nevember 22, 2019. \\ Accepted: April 15, 2020.}

doi:10.3324/haematol.2019.243543

Check the online version for the most updated information on this article, online supplements, and information on authorship \& disclosures: www. haematologica.org/content/105/6/1494

(C)2020 Ferrata Storti Foundation

Material published in Haematologica is covered by copyright. All rights are reserved to the Ferrata Storti Foundation. Use of published material is allowed under the following terms and conditions:

https://creativecommons.org/licenses/by-nc/4.0/legalcode. Copies of published material are allowed for personal or internal use. Sharing published material for non-commercial purposes is subject to the following conditions:

https://creativecommons.org//icenses/by-nc/4.0/legalcode, sect. 3. Reproducing and sharing published material for commercial purposes is not allowed without permission in writing from the publisher.

\section{ABSTRACT}

T he introduction of anti-CD20 monoclonal antibodies such as rituximab, ofatumumab, or obinutuzumab improved the therapy of Bcell malignancies even though the precise physiological role and regulation of CD20 remains unclear. Furthermore, CD20 expression is highly variable between different B-cell malignancies, patients with the same malignancy, and even between intraclonal subpopulations in an individual patient. Several epigenetic (EZH2, HDAC1/2, HDAC1/4, HDAC6, complex Sin3A-HDAC1) and transcription factors (USF, OCT1/2, PU.1, PiP, ELK1, ETS1, SP1, NFкB, FOXO1, CREM, SMAD2/3) regulating $\mathrm{CD} 20$ expression (encoded by MS4A1) have been characterized. CD20 is induced in the context of microenvironmental interactions by CXCR4/SDF1 (CXCL12) chemokine signaling and the molecular function of $\mathrm{CD} 20$ has been linked to the signaling propensity of B-cell receptor (BCR). CD20 has also been shown to interact with multiple other surface proteins on B cells (such as CD40, MHCII, CD53, CD81, CD82, and CBP). Current efforts to combine anti-CD20 monoclonal antibodies with BCR signaling inhibitors targeting BTK or PI3K (ibrutinib, acalabrutinib, idelalisib, duvelisib) or BH3-mimetics (venetoclax) lead to the necessity to better understand both the mechanisms of regulation and the biological functions of CD20. This is underscored by the observation that CD20 is decreased in response to the "BCR inhibitor" ibrutinib which largely prevents its successful combination with rituximab. Several small molecules (such as histone deacetylase inhibitors, DNA methyl-transferase inhibitors, aurora kinase $\mathrm{A} / \mathrm{B}$ inhibitors, farnesyltransferase inhibitors, FOXO1 inhibitors, and bryostatin-1) are being tested to upregulate cellsurface CD20 levels and increase the efficacy of anti-CD20 monoclonal antibodies. Herein, we review the current understanding of CD20 function, and the mechanisms of its regulation in normal and malignant $\mathrm{B}$ cells, highlighting the therapeutic implications.

\section{Introduction}

The approval of the anti-CD20 antibody rituximab by the Food and Drug Administration in 1997 was a conceptual breakthrough in the treatment of B-cell malignancies. Rituximab improved progression-free survival and overall survival rates when added to chemotherapy in "mature" B-cell leukemias and lymphomas such as chronic lymphocytic leukemia (CLL), follicular lymphoma, and diffuse large B-cell lymphoma (DLBCL), and this proved that monoclonal antibodies could be used in cancer treatment. ${ }^{1}$ Additionally, rituximab maintenance therapy has been introduced for some of these diseases. Based on the success of rituximab, new engineered anti-CD20 monoclonal antibodies, namely ofatumumab and obinutuzumab, were developed. Preclinical studies suggest that these new anti-CD20 monoclonal antibodies are superior to rituximab for some mechanisms of action. ${ }^{2}$ Anti-CD20 monoclonal antibodies might act through several mechanisms (Figure 1) including complement-dependent cytotoxicity (CDC), complement-dependent cellular cytotoxicity, antibody-dependent cellular cytotoxicity (ADCC), antibody- 
dependent cellular phagocytosis, and direct apoptosis induction, as has been elegantly reviewed by others. ${ }^{3,4}$ All these mechanisms were observed in vitro and/or in animal models, and likely act in vivo in patients as well, but their relative contribution to the clinical effects of the different anti-CD20 monoclonal antibodies is still debated. It is also unclear why the application of novel engineered monoclonal antibodies provides clinical benefit in comparison to rituximab in some B-cell malignancies, but not in others. For example in CLL patients, obinutuzumab is superior to rituximab when combined with chlorambucil, as judged by the number of complete remissions and prolonged progression-free survival. ${ }^{5}$ A much less significant improvement in progression-free survival has also been demonstrated in previously untreated follicular lymphoma patients treated with obinutuzumab-based chemoimmunotherapy compared to rituximab-based chemoimmunotherapy. ${ }^{6,7}$ Finally, a phase III clinical study demonstrated no improvement in progression-free survival in a large cohort of treatment-naive DLBCL patients when comparing obinutuzumab plus CHOP (cyclophos- phamide, adriamycin, vincristine and prednisone) versus rituximab plus $\mathrm{CHOP}^{8}$ It is important to note that in these trials, obinutuzumab was used at doses and schedules quite different from those of rituximab. For example, in the CLL trial ${ }^{5}$ a flat obinutuzumab dose of 1000 $\mathrm{mg} /$ patient was used (on days 1, 8, and 15 of cycle 1 and on day 1 of cycles 2-6), while rituximab was used at a dose of $375 \mathrm{mg} / \mathrm{m}^{2}$ on day 1 of cycle 1 and $500 \mathrm{mg} / \mathrm{m}^{2}$ on day 1 of cycles 2-6. Overall, in this CLL trial the median cumulative rituximab dose per patient was $64 \%$ of the obinutuzumab dose (these two monoclonal antibodies have a nearly identical molecular weight).

Currently, efforts have shifted from adding anti-CD20 monoclonal antibodies to chemotherapy to combining them with novel drugs, such as B-cell receptor (BCR) signaling inhibitors (ibrutinib, idelalisib, etc.) ${ }^{9}$ or BH3-mimetics inhibiting BCL2 (venetoclax), ${ }^{10}$ and also the development of CD20 targeting chimeric antigen receptor $T$ cells. ${ }^{11}$ It is essential to understand the mechanism of CD20 regulation and function thoroughly and to elucidate the mechanism of action of monoclonal antibodies in

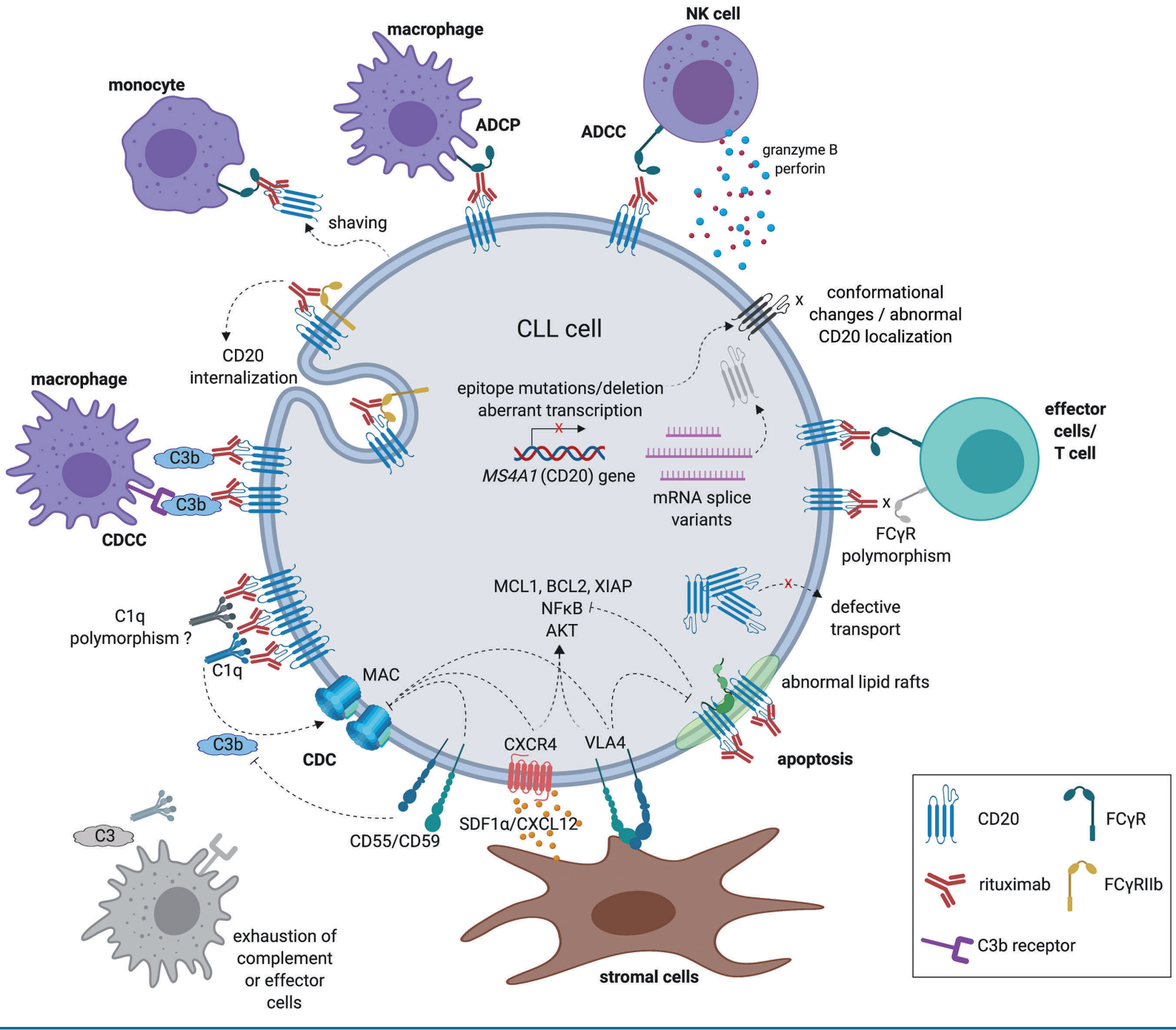

Figure 1. Summary of the known mechanisms of action of anti-CD20 monoclonal antibodies and an overview of potential factors affecting resistance to anti-CD20 therapy in malignant B cells. Anti-CD20 monoclonal antibodies act through several mechanisms, including complement-dependent cytotoxicity (CDC), complementdependent cellular cytotoxicity (CDCC), antibody-dependent cellular phagocytosis (ADCP), antibody-dependent cellular cytotoxicity (ADCC), and induction of direct apoptosis. 
order to fully exploit their therapeutic potential. This is underscored by the recent disappointing results of clinical trials testing rituximab's addition to the BTK inhibitor ibrutinib in CLL, which showed practically no benefit of such a combination. ${ }^{12}$ Here we summarize the research describing the regulation and function of CD20 in normal and malignant B cells, and the therapeutic implications of these observations, including the relevance for the combination of "BCR inhibitors" with anti-CD20 monoclonal antibodies.

\section{CD20 gene and protein structure}

CD20 is a $33-37 \mathrm{kDa}$ non-glycosylated protein expressed on the surface of normal and malignant $B$ lymphocytes, and belongs to the MS4A (membrane-spanning 4-domain family A) protein family. ${ }^{13}$ To date, $18 \mathrm{MS} 4 \mathrm{~A}$ family members have been identified, besides MS4A1 (encoding CD20), also the high-affinity immunoglobulin $\mathrm{E}$ receptor $\beta$ subunit (MS4A2/FceRI $\beta$ ) or HtM4 gene (MS4A3) (reviewed by Eon $\mathrm{Kuek}^{14}$ ). MS4A proteins are transmembrane molecules and they are predicted to share a similar polypeptide sequence and overall topological structure. The majority of MS4A genes, including MS4A1, are localized within a cluster on chromosome 11q12 in humans (chromosome 19 in mice), and two members from a closely related TMEM176 gene family were identified in chromosome region $7 \mathrm{q} 36.1 .^{14}$

The MS4A1 gene is $16 \mathrm{~kb}$ long, comprises eight exons, and several different CD20 mRNA transcripts have been annotated. ${ }^{13}$ The dominant CD20 mRNA variant is $2.8 \mathrm{~kb}$ long and uses all eight exons, whereas the second most common form is 263 bases shorter, as it skips exon II. A minor $3.5 \mathrm{~kb}$ mRNA results from splicing exons in the upstream region into an internal $3^{\prime}$ splice site located in exon I. However, all three transcripts are translated into identical full-length CD20 protein as the translation start codon is localized within exon III. Moreover, other alternative transcripts were identified in malignant $B$ cells, some of them encoding truncated forms of $\mathrm{CD} 20$ protein leading to impaired binding of anti-CD20 monoclonal antibodies. ${ }^{15,16}$

CD20 protein consists of four hydrophobic transmembrane domains, one intracellular and two extracellular domains (large and small loops) with both $\mathrm{N}$ - and C- termini residing within the cytosol. ${ }^{14}$ Three CD20 isoforms $(33,35$ and $37 \mathrm{kDa})$ resulting from different phosphorylation have been identified, and CD20 phosphorylation was reported to be higher in proliferating malignant $B$ cells than in resting B cells. ${ }^{17}$ Normally, CD20 does not form hetero-oligomers, ${ }^{18}$ but exists on the cell surface as homo-

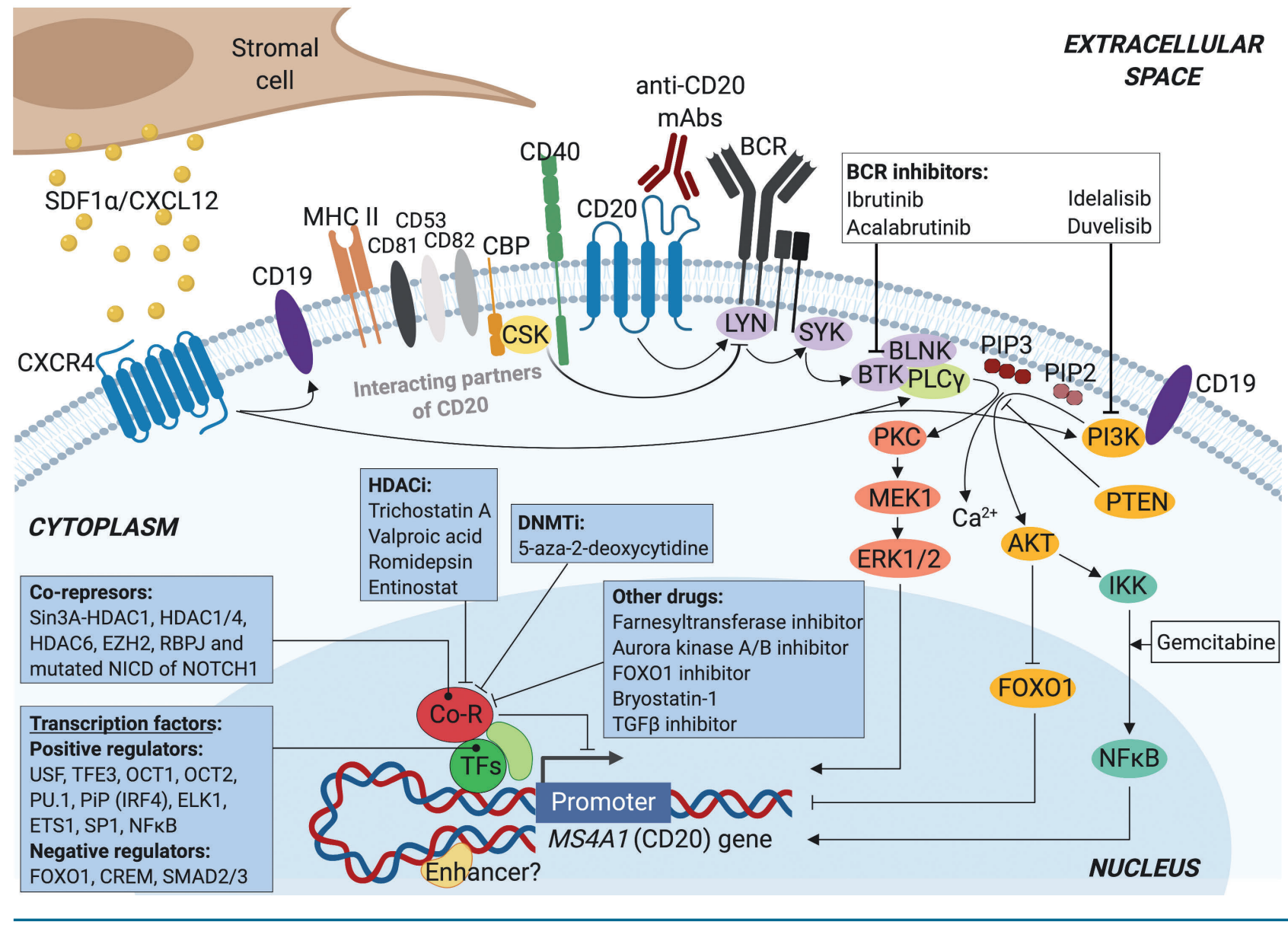

Figure 2. A schematic view of interacting partners of CD20 on cell membrane and mechanisms of CD20 gene (MS4A1) regulation in malignant B cells. mAbs: monoclonal antibodies; BCR: B-cell receptor; HDACi: histone deacetylase inhibitors; DNMTi: DNA methyl-transferase inhibitors; NICD: NOTCH1 intracellular domain; TGF $\beta$ : transforming growth factor $\beta$. 
dimeric and homo-tetrameric oligomers associated with other cell-surface and cytoplasmic proteins contributing to the signal transduction. ${ }^{17,19,20}$ Tetraspanin proteins tend to associate with multiple other proteins in membrane microdomains (Figure 2). ${ }^{21}$ Energy transfer experiments indicate that CD20 is in close proximity to other tetraspan molecules, such as CD53, CD81, and CD82, forming supramolecular complexes (Figure 2). ${ }^{22}$ CD20 is also known to be physically coupled to major histocompatibility complex class II (MHCII), CD40 molecule, BCR, and the C-terminal src kinase-binding protein (CBP) that interacts with Src kinases such as LYN, FYN, and LCK (Figure 2) ${ }^{20,23,24}$ Besides the transmembrane form of CD20, circulating CD20 was reported in CLL patients' plasma; ${ }^{25}$ however, this is likely to be part of a larger protein complex or a cell membrane fragment originating from cell breakdown.

CD20 is a general B-cell marker expressed by the majority of $B$ cells starting from late pre-B lymphocytes (it is not expressed by pro-B lymphocytes), and its expression is lost in terminally differentiated plasmablasts and plasma cells. Recently, a subset of CD20 $0^{+} \mathrm{T}$ cells with immuneregulatory and pro-inflammatory activity has been described; however, the clinical relevance of this remains to be determined. ${ }^{26}$ In B-cell malignancies, the level of CD20 expression is extremely variable depending on the specific neoplasm, with the lowest CD20 expression usually being observed in patients with CLL and the highest CD20 cell-surface expression on DLBCL and hairy cell leukemia cells. ${ }^{27,28}$ Within CLL, it was noted that CD20 expression was also relatively higher in a disease subtype with a mutated variable region of immunoglobulin gene (IGHV) than in the subtype with unmutated IGHV. ${ }^{29}$ Some studies described that higher CD20 expression levels correlate with longer overall survival in patients with B-cell lymphomas treated with rituximab, ${ }^{30,31}$ although this remains controversial. ${ }^{32,33}$ Notably, CD20 levels are heterogeneous not only among patients with the same malignancy, but also within the intraclonal cell subpopulations in an individual patient. ${ }^{34}$

\section{CD20 function: a link to B-cell receptor signaling and microenvironmental interactions}

The biological function of CD20 in B cells and its physiological ligand, if any, remain unclear. Some light on CD20 function has been shed by a case report of a patient with a common variable immunodeficiency and CD20 loss caused by a homozygous mutation in an exon 5 splicing site of MS4A1. The mutation led to alternative splicing with complete deletion of exon 5 and insertion of intron sequences and thus a truncated form of MS4A1 mRNA. ${ }^{35}$ Due to this homozygous mutation, the patient completely lacked cell-surface CD20. This did not disturb precursor B-cell differentiation in the bone marrow, as the patient had normal serum IgM levels and normal B-cell numbers. However, CD20 deficiency resulted in a reduced number of circulating memory B cells, reduced isotype switching of Ig, and decreased IgG antibody levels. In agreement with this observation, challenging the patient's primary B cells in vitro using $\mathrm{T}$-dependent and $\mathrm{T}$ independent antigens led to the normal proliferation and secretion of $\operatorname{IgM}$ but reduced production of $\operatorname{IgG}$. Given these data it is surprising that after repeated vaccinations the patient displayed a reduced ability to respond to $\mathrm{T}$ independent antigens (pneumococcal polysaccharide vac- cine), but a normal reaction to $\mathrm{T}$-dependent antigens (anti-tetanus toxoid IgG).

Cases of a homozygous mutation in the MS4A1 gene in humans are extremely rare, which prompted the generation of mouse models. This is a reasonable approach, since human and mice CD20 proteins share most structural features and a conserved amino acid sequence ( $75 \%$ homology) with only a few structural modifications in the transmembrane and $\mathrm{N}$ - and C-terminal cytoplasmic domains. ${ }^{36} \mathrm{CD} 20$ in both humans and mice is $\mathrm{B}$ cell specific, being first expressed by late pre-B cells in the bone marrow, predominantly after Ig heavy chain rearrangement. Uchida et al. created a mouse model with a homozygous mutation in the MS4A1 gene. ${ }^{36}$ These CD20-less mice had normal B-cell differentiation, isotype switching, maturation, mitogen-induced proliferation, and tissue localization. Similarly, CD20 deletion was not observed to have any effect on proliferation and differentiation in mice with MS4A1 disruption, generated by Neuberger's group. ${ }^{37}$ CD20 $\%$ mice immunized with Tdependent antigens showed impaired humoral immunity and primary and secondary immune responses connected with reduced numbers of germinal center B cells. ${ }^{38}$ Altogether, these studies in human and murine CD20deficient B cells suggest that CD20 is required for both optimal T-independent humoral immunity, and also for a response to $\mathrm{T}$-dependent antigens. However, it should be taken into consideration that the $\mathrm{T}$-dependent immune response might be impaired due to the loss of CD20 in a small $\mathrm{CD}_{20} 0^{+}$population of $\mathrm{T}$ cells whose specific role in the immune system remains unclear. ${ }^{26}$ Overall, the relatively mild phenotype resulting from CD20 loss in humans and mice is somewhat surprising since CD20 was reported to be physically and functionally coupled to MHCII and CD40 (Figure 2), ${ }^{23}$ which are both critical for $\mathrm{B}-$ and $\mathrm{T}$-cell interactions.

The development of humoral immunity requires a functional BCR signaling pathway, and CD20 was reported to be co-localized in lipid rafts ${ }^{39}$ and to interact directly physically with BCR. ${ }^{20}$ Additionally, it has been observed that CD20 becomes heavily phosphorylated after mitogen stimulation, and it has been proposed that it might function as a calcium channel and be involved in B-cell activation. ${ }^{17,19}$ This is in line with in vitro data showing that BCR-activated calcium flux was reduced after siRNAmediated CD20 down-modulation in human B-cell lines. $^{34,40}$ Moreover, direct CD20 crosslinking induces acute signaling similar to BCR crosslinking, including calcium flux, and overlapping transcription patterns in human lymphoma cell lines. ${ }^{41,42}$ Kheirallah et al. also demonstrated that pretreatment of lymphoma cell lines with rituximab interferes with BCR signaling cascade stimulation, suggesting that both cell-surface proteins might share the same signaling pathway components and activate negative feedback regulatory mechanisms, including BCR downmodulation. ${ }^{43}$ We and others have shown that levels of cell-surface CD20 on primary CLL cells are correlated (and possibly co-regulated) with cellsurface BCR expression. ${ }^{34}$ Additionally, we observed in vivo that CLL cells that have recently exited the lymph node microenvironment to the peripheral blood are characterized by a marked upregulation of CD20 levels. ${ }^{44}$ This stems from the activation of CXCR4 by SDF1 chemokine, which leads to transcriptional activation of CD20 expression. Moreover, CD20 cell-surface levels are 
induced in CLL cells treated by microenvironmental factors such as IL4, TNF $\alpha$, INF $\alpha$ or GMCSF in vitro ${ }^{45-47}$ (and our unpublished data).

CD20 silencing in malignant B cells revealed that CD20 affects the phosphorylation of multiple BCR-associated kinases and proteins after BCR-ligation (LYN, SYK, GAB1, and ERK). ${ }^{34}$ This suggests that both CD20 and BCR are induced in immune niches ${ }^{34}$ to allow effective and strong BCR activation by an antigen or CD20 might also be involved in some form of "tonic" BCR signaling..$^{48}$ This has important implications for combining BCR inhibitors with antibodies targeting CD20. We have shown that inhibiting BTK interferes with CXCR4 signaling in CLL cells and thus leads to very significant repression of CD20 expression in CLL cells. This might partially explain the lack of clinical benefit from adding rituximab to ibrutinib. ${ }^{12}$ Ibrutinib was recently tested and approved in combination with a more potent anti-CD20 monoclonal antibody, namely obinutuzumab, ${ }^{49}$ whose efficacy is less affected by lower levels of CD20 on the cell-surface. We also suggest that PI3K inhibition, like BTK inhibition, might lead to the downmodulation of CD20, but this remains to be formally proven, and the implications for the therapeutic combination of rituximab with PI3K inhibitors (including idelalisib) or other BTK inhibitors (such as acalabrutinib) are unclear.

Altogether, functional studies suggest that CD20 is physiologically directly required for efficient BCR signaling in B cells. This is also in line with some data from the CD20 mouse models. In Uchida's CD20 mice model, cell-surface IgM expression on both mature and immature $\mathrm{B}$ cells was $20-30 \%$ lower than that on B cells from wildtype littermates, which was connected with reduced BCRand CD19-dependent intracellular calcium mobilization. ${ }^{36}$ In a study by Morsy et al., the reduction in BCR-associated calcium mobilization in CD20\% murine B cells was proposed to be caused by a defect in calcium transport rather than in its release from intracellular stores. ${ }^{38}$ In our opinion, there is a sufficient body of evidence suggesting that CD20 is involved in BCR signaling, but it is unclear whether this is related to its putative function as a calcium channel and/or other function(s). Similarly, it is not clear if other molecular pathways or B-T-cell interactions might be affected by CD20 levels on the cell-surface of B cells.

\section{Regulation of CD20 transcription and its "therapeutic modulation"}

Rituximab is one of the most effective and widely used therapeutic monoclonal antibodies, but malignant B cells can become relatively resistant to such therapy. Mechanisms of malignant B cells' resistance to anti-CD20 monoclonal antibodies include insufficient CDC activity due to increased expression of regulatory proteins CD55, CD59 or factor $\mathrm{H}^{50,51}$ less effective ADCC in cases with specific Fc $\gamma$ RIII polymorphism, ${ }^{52}$ exhaustion of cytotoxic mechanisms (such as complement/effector cells), ${ }^{53,54}$ polymorphism in the complement component $\mathrm{C} 1 \mathrm{qA},{ }^{55}$ or abnormal composition and localization of lipid rafts and thus impaired rituximab-induced apoptosis (Figure 1). ${ }^{56}$ Nevertheless, one of the most straightforward and frequent causes of resistance to anti-CD20 monoclonal antibodies is reduced CD20 expression, which can be due to (de)regulation of transcriptional, post-transcriptional, or post-translational mechanisms (including CD20 protein transport to the cell surface ${ }^{57}$ ).

Regarding transcriptional regulation, the MS4A1 gene lacks several regulatory elements typical of other B-cell specific genes, including TATA and CAAT box. The

Table 1. Positive and negative regulators of MS4A1 (CD20 gene) transcription.

\begin{tabular}{|c|c|}
\hline Positive regulators ${ }^{\text {Ref }}$ & Negative regulators ${ }^{\text {Ref }}$ \\
\hline 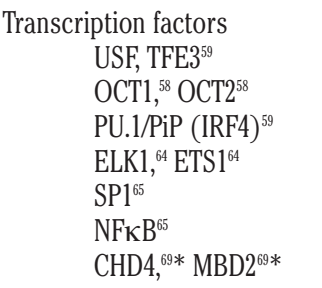 & $\begin{array}{l}\text { FOXO1 }^{70} \\
\text { CREM }^{69} \\
\text { SMAD2/39 } \\
\text { MYC }^{67}\end{array}$ \\
\hline $\begin{array}{c}\text { Epigenetic regulators } \\
\text { Unknown }\end{array}$ & $\begin{array}{l}\text { Sin3A-HDACl }{ }^{76} \\
\text { EZH2 }^{80} \\
\mathrm{HDACl}^{81} \\
\text { HDAC6 } \\
\text { RBPJ and mutated NICD of NOTCH1 }\end{array}$ \\
\hline
\end{tabular}

* The DNA binding site in the MS4A1 promoter has not been defined. NICD: NOTCH1 intracellular domain.

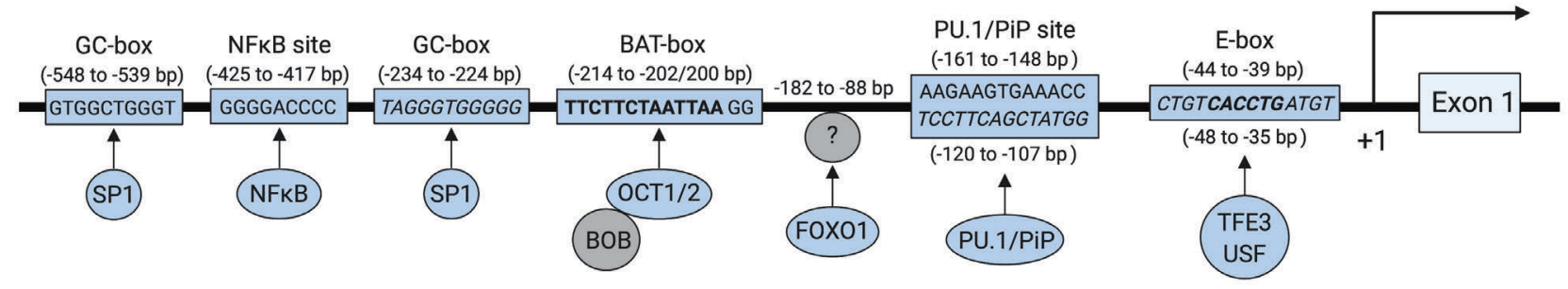

Figure 3. A schematic of the proximal region of MS4A1 promoter with transcription factor binding sites. Several regulatory elements differ in nucleotide sequence when comparing data from literature and the TRANSFAC database. Shimizu et al. ${ }^{65}$ described the GC-box binding SP1 as being located in a region between bases 548 and -539 , but the TRANSFAC database identified a GC-box in a position -234 to -224 bp [based on the SP1 chromatin immunoprecipitation sequencing data (ENCODE ID: ENCSRO0OBHK)]. A BAT-box was identified by Thévenin et al. ${ }^{58}$ in the proximal promoter region located between bases -214 and -202 (in bold), while others describe it between bases -214 and $-200 . .^{59,65}$ The PU.1/PiP binding site was originally defined as a sequence between -161 and -148 bp, ${ }^{59}$ but TRANSFAC predicts it in the region from -120 to $-107 \mathrm{bp}$ (in italics). The E-box sequence is usually described as the CACCTG sequence between -44 and -39 bp (in bold) ${ }^{59,62,65}$ but the TRANSFAC database suggests (based on ENCODE ID: ENCSROOOBGI) a longer sequence from -48 to -35 bp (in italics). FOXO1 was suggested as being recruited to the MS4A1 promoter indirectly by the DNA-binding element between bases -182 and $-88 .{ }^{70} \mathrm{NFKB}$ binds into the region of the MS4A1 promoter between -425 and -417 bp. $^{62}$ 
known positive regulatory elements present in the MS4A1 promoter include an E-box motif (binding $\mu \mathrm{E} 3-$ specific transcription factors such as USF and TFE3), "PU.1/PiP" binding site and a BAT box (Figure 3, Table 1). ${ }^{58,59}$ The BAT box is a sequence element present in the most proximal region and serves as a binding site for the transcription factors OCT1 and OCT2 with a B-cell restricted co-activator $\mathrm{BOB}$ (Figure 3 , Table 1). ${ }^{58,60}$ The BAT element is important for the high constitutive expression of CD20 in mature B cells and the induction of CD20 in pre-B cells. ${ }^{58}$ The "PU.1/PiP" binding site is a putative site for transcription factors belonging to the ETS family (e.g. PU.1) and protein PiP (IRF4) (Figure 3, Table 1). PiP is recruited to this DNA binding site indirectly by phosphorylated PU.159 and a "PU.1/PiP" binding site seems to be critical for CD20 expression as it is occupied only in CD20-positive B cells. Additionally, PU.1/Pip are downregulated during plasma cell differentiation, ${ }^{61}$ and mutations in this binding site nearly completely abolished the promoter activity of MS4A1. ${ }^{59}$ Moreover, transcriptional CD20 activation in primary CLL and nonHodgkin lymphoma (NHL) B cells was associated with increased PU.1 and OCT2 binding to the MS4A1 promoter in response to farnesyltransferase inhibition. ${ }^{62}$ Downregulating PU.1 expression by overexpression of its negative regulator, namely FLT3, also led to lower CD20 expression in CLL cells and vice versa. ${ }^{63}$

Several transcription factors from the ETS family, such as ELK1 and ETS1, were observed to be activated in an ERK-dependent manner and enhance CD20 cell-surface expression in B-NHL cell lines and primary CLL cells after bryostatin-1 treatment in vitro (which activates the MEK1/ERK-1/2 pathway via PKC) (Figure 2, Table 1). ${ }^{64}$ Furthermore, it was proposed that NFKB might positively regulate CD20 expression ${ }^{62,65}$ and gemcitabine treatment of DLBCL cell lines augmented CD20 expression together with NFKB signaling activation (Figures 2 and 3, Table 1). ${ }^{66}$ Chromatin immunoprecipitation sequencing analysis also revealed MS4A1 as a direct MYC target gene in Burkitt lymphoma cell lines (Table 1), and MYC silencing resulted in CD20 upregulation. ${ }^{67}$ The repression of CD20 by $\mathrm{MYC}$ is surprising and remains to be confirmed in other lymphoma cell types, since B-cell activation (also leading to MYC expression) is generally known to induce CD20 expression in B cells. ${ }^{68}$ To reveal other factors regulating CD20 expression, Slabicki et al. ${ }^{69}$ performed a genome-wide RNA interference screening using a library of small hairpin RNAs delivered into Raji cells (Burkitt lymphoma cell line) by lentiviral vectors. They identified 37 potential CD20 repressors and 51 activators, among them CHD4 and MBD2 as novel MS4A1 inducers (Table 1). Both CHD4 and MBD2 are members of the nucleosome remodeling deacetylase complex, which plays an important role in the regulation of gene transcription. This screening also revealed CREM as the top candidate for CD20 repression, and the presence of three halfcAMP response elements in MS4A1 promoter sites (TGACG) led to the notion that cAMP-mediated signal transduction plays a role in CD20 transcriptional repression. Most recently, FOXO1 transcription factor was described as a negative MS4A1 transcription regulator in lymphoma B cells (Figures 2 and 3, Table 1). ${ }^{70}$ This is in agreement with the observation that DLBCL patients with activating FOXO1 mutations have shorter overall survival upon rituximab-based therapy. ${ }^{71}$ As the exact localization of the putative FOXO1 binding site in the MS4A1 promoter was not determined, it is believed that FOXO1 binds indirectly to the DNA-binding element between -182 and $-88 \mathrm{bp}$ (Figure 3). ${ }^{70}$ These data (and our unpublished data) suggest that FOXO1 inhibitors might theoretically be combined with anti-CD20 antibodies to induce CD20 expression and potentiate the effect of the monoclonal antibodies. Similarly, other groups have proposed that inhibiting aurora kinase A/B could also lead to upregulation of CD20 and potentiation of rituximab's clinical efficacy. ${ }^{72,73}$

It is not surprising that several recent studies suggested that CD20 is at least partially regulated by epigenetic mechanisms. Tomita et al. demonstrated that treating a CD20-negative B-cell line with the histone deacetylase (HDAC) inhibitor trichostatin A resulted in robust upregulation of CD20 mRNA and protein..$^{74}$ In vitro treatment of primary cells obtained from relapsed CD20-negative BNHL patients using the DNA methyl-transferase (DNMT) inhibitor 5-aza-2-deoxycytidine also led to the stimulation of MS4A1 mRNA and cell-surface expression within 3 days, and restoration of rituximab sensitivity. ${ }^{75}$ Despite the fact that CD20 stimulation by DNMT inhibitors was described both in vitro ${ }^{75,76}$ and in vivo in patients with B-cell malignancies, ${ }^{77} \mathrm{CD} 20$ is less likely to be regulated by CpG (de)methylation as its promoter region does not contain any $\mathrm{CpG}$ islands up to $\sim 5 \mathrm{~kb}$ upstream from the transcription start site. ${ }^{76}$ However, it is plausible that DNMT inhibition regulates the methylation status of transcription factors critical for MS4A1 transcription, or some more distant genomic regions (enhancers) are involved in MS4A1 transcription. Furthermore, it was reported that a Sin3A-HDAC1 co-repressor complex is recruited to the MSA41 promoter in CD20-negative B-cell lines (Figure 2, Table 1). ${ }^{76}$ This complex dissociates from the promoter with 5-aza-2-deoxycytidine and trichostatin A treatment, resulting in histone acetylation and partial restoration of CD20 expression. Shimizu et al. showed that HDAC inhibitors (valproic acid or romidepsin) are able to induce CD20 expression in B-cell lines through MS4A1 promoter hyperacetylation and recruit the SP1 transcription factor within 48 hours (Figures 2 and 3, Table 1). ${ }^{65}$ At the moment, several ongoing clinical trials are evaluating the efficacy of epigenetic modulators in combination with rituximab (Table 2). In the VALFRID study, pretreatment with valproic acid before first-line therapy with $\mathrm{CHOP}$ plus rituximab in DLBCL patients resulted in histone acetylation, CD20 upregulation at the mRNA and cellsurface levels ${ }^{78}$ and improved overall survival. ${ }^{79}$ In contrast, the analysis of three CLL patients from the PREVAIL study showed no CD20 induction upon pretreatment with valproic acid.$^{80}$ A plausible explanation might be that valproic acid induces a bivalent $M S 4 A 1$ promoter status in primary CLL cells in vivo as it induces histone acetylation, but also transient recruitment of the transcriptional repressor EZH2 to the MS4A1 promoter (Figure 2, Table 1). Administering a DNMT inhibitor and pan-HDAC inhibitor (valproic acid, romidepsin, trichostatin A, SAHA) stimulates CD20 expression and might improve anti-CD20 therapy in vivo, at least in some patients with B-NHL. However, the clinical use of pan-HDAC inhibitors is hindered by adverse effects ${ }^{77,79}$ and thus the involvement of individual HDAC molecules and selective HDAC inhibitors are undergoing pre-clinical studies. Recently, entinostat, a selective HDAC1/4 inhibitor, was 
Table 2. List of novel drugs combined with anti-CD20 monoclonal antibodies in B-cell malignancies.

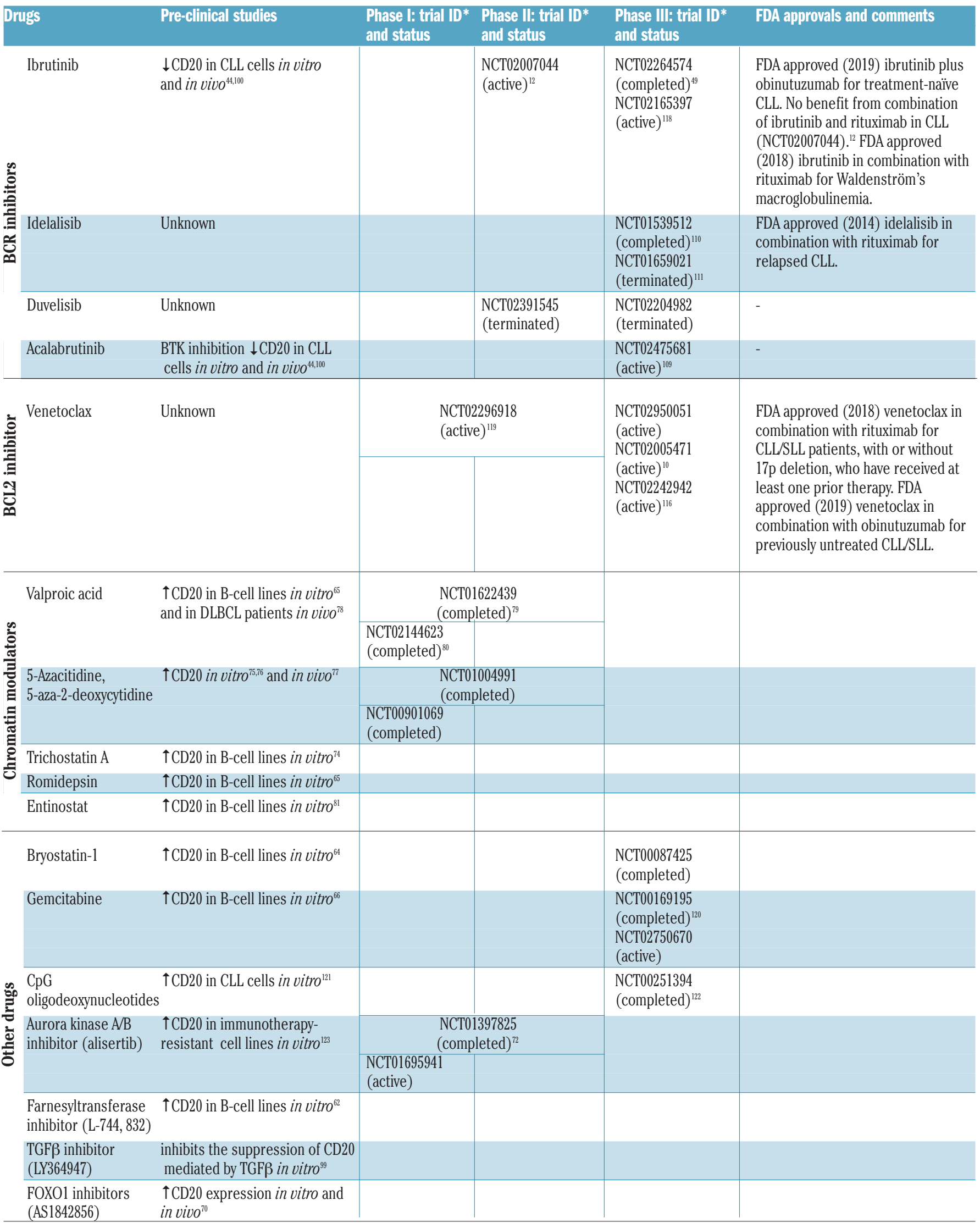

$\uparrow$ : induction of expression; $\downarrow$ : repression of expression;-: no decision; *: ID on clinicaltrials.gov; ID: identity; FDA: Food and Drug Administration; CLL: chronic lymphocytic leukemia; BCR: B-cell receptor; BTK: Bruton tyrosine kinase; SLL: small lymphocytic lymphoma; DLBCL: diffuse large B-cell lymphoma; TGF $\beta$ : transforming growth factor- $\beta$. 
reported to upregulate CD20 and improve rituximab efficacy both in vitro and in a mouse model (Figure 2, Table 1). ${ }^{81}$ Additionally, Bobrowicz et al. identified HDAC6 as a novel repressor of CD20 expression in B-cell lines and primary CLL cells (Figure 2, Table 1). ${ }^{82}$ HDAC6 was shown to be overexpressed in CLL cells and its inhibition augmented the efficacy of anti-CD20 monoclonal antibodies in vitro and improved survival of complement-, NK celland macrophage-competent mice (SCID Fox Chase mice) injected with Raji cells and treated with rituximab. ${ }^{82}$ However, it seems that HDAC6 inhibitor does not induce MS4A1 transcription, but only increases MS4A1 mRNA translation. Its potential clinical use is, therefore, likely limited to malignancies that have highly active MS4A1 transcription but escape anti-CD20 antibodies by preventing its translation. This is not likely in most CLL cases, although, one report has suggested that MS4A1 mRNA might be repressed post-transcriptionally by microRNAs in CLL. ${ }^{83}$

\section{Regulation of CD20 levels on the cell-surface during therapy}

Besides transcriptional and epigenetic regulation, several studies have demonstrated CD20 downmodulation on the B-cell surface in response to anti-CD20 therapy (Figure 1). One of these mechanisms is called "shaving". Monocytes and macrophages recognize rituximab binding to CD20 and remove this complex from the B-cell surface via the FcrRI-dependent process of endocytosis called trogocytosis ${ }^{53}$ and this was observed in CLL patients treated with rituximab in vivo (Figure 1). ${ }^{53,84,85}$ Alternatively, the acute change in CD20 levels in the malignant B-cell population after rituximab infusion might be partially due to elimination of those cells with the highest CD20 levels. Indeed, we have shown that after rituximab infusion in vivo, the antibody primarily targets and eliminates a subpopulation of CLL cells with the highest levels of CD20 via CDC, whereas many CLL cells with pre-therapy low CD20 levels survive. ${ }^{34}$ Importantly, the CLL cells with the highest cell-surface CD20 levels are also those with the highest BCR signaling propensity and also represent the vast majority of Ki67positive cells in peripheral blood. ${ }^{34}$ This "targeting" of the most aggressive intraclonal CLL cell subpopulation at least partially explains the good clinical efficacy of rituximab. It remains to be determined whether rituximab is also targeting specific intraclonal cell subpopulations in diseases such as follicular lymphoma and DLBCL, in which malignant cells have relatively homogenously higher CD20 cell-surface levels.

Another mechanism reducing CD20 expression on B cells in response to anti-CD20 therapy is known as antigenic modulation (Figure 1). ${ }^{86}$ This refers to the active internalization and subsequent degradation of CD20/monoclonal antibody complexes demanding energy and cytoskeleton remodeling. Importantly, only type I anti-CD20 monoclonal antibodies induce marked antigenic modulation. These anti-CD20 monoclonal antibodies (e.g. rituximab and ofatumumab) recognize and bind CD20 epitope in a different orientation than type II antibodies (obinutuzumab) and are able to redistribute CD20 into lipid rafts on the plasma membrane..$^{87,88}$ Type I antiCD20 monoclonal antibodies also have an approximately two-fold higher capacity to bind CD20 epitope, which makes them prone to internalization and proteolytic degradation..$^{86,89}$ Moreover, the extent of antigenic modulation depends on the type of B-cell malignancy. The most rapid internalization can be seen in CLL cells, followed by mantle cell lymphoma cells, while follicular lymphoma and DLBCL cells show relatively lower rates of antigen internalization. ${ }^{86} \mathrm{Lim}$ et al. suggested that different rates of internalization in B-cell malignancies are due to different levels of inhibitory FcyRIIb on B cells (predominantly expressed on CLL and mantle cell lymphoma cells). ${ }^{90}$ Rituximab was proposed to crosslink CD20 and Fc $\gamma$ RIIb on the same B cell, resulting in Fc $\gamma$ RIIb phosphorylation, and internalization of these complexes into lysosomes for their degradation.

The selection pressure caused by rituximab therapy can also lead to the emergence of malignant B-cell clones that are relatively or fully negative for cell-surface CD20 expression (Figure 1). In some DLBCL patients, mutations in the MS4A1 coding sequence were identified; however, mutations involving rituximab epitope are extremely rare. ${ }^{91}$ Terui et al. analyzed CD20 mutations in samples obtained from patients with previously untreated or relapsed/refractory B-NHL and found MS4A1 mutations in 11 out of 50 patients $(22 \%) .{ }^{92}$ Importantly, in four cases $(8 \%)$, such mutations resulted in a C-terminal truncated form of CD20 protein and reduced its cell-surface expression. Nakamaki et al. also reported a case of a relapsed DLBCL patient with a homozygous MS4A1 gene deletion after rituximab-based therapy. ${ }^{93}$

Notably, some recurrent genetic mutations in patients with B-cell malignancies might affect CD20 levels, and be favored during therapy. In a clinical trial comparing fludarabine and cyclophosphamide treatment with fludarabine, cyclophosphamide and rituximab treatment, it was found that NOTCH1 mutations are associated with a relative resistance to the anti-CD20 therapy. ${ }^{94}$ Pozzo et al. showed that NOTCH1-mutated CLL cells are characterized by a lower CD20 expression in comparison to that of NOTCH1-wildtype CLL cells. ${ }^{95}$ Mutations in NOTCH1 intracellular domain (NICD) result in dysregulation of HDAC-mediated epigenetic repression of CD20 through interactions with the RBPJ transcription factor. RBPJ acts as a negative regulator when forming a complex with HDAC1/2; however, accumulation of mutated NOTCH1 in the nucleus results in the preferential formation of NICD-RBPJ activating complex and higher HDAC1/2 levels available for interactions with an MS4A1 promoter.

Recently, microenvironmental interactions in various Bcell malignancies were brought into focus as these provide essential pro-proliferative and pro-survival signals and promote drug resistance (reviewed by Seda \& $\left.\mathrm{Mraz}^{48}\right)$. Interactions between mesenchymal stromal cells and CLL cells were shown to protect the leukemic cells from rituximab-induced $\mathrm{CDC}^{96}$ and direct apoptosis, ${ }^{97}$ and this can be therapeutically targeted by integrin inhibition (Figure 1). ${ }^{97}$ These observations led to the coining of the term "cell adhesion-mediated antibody resistance" as an analogy to the long-known "cell adhesion-mediated drug resistance", which refers to resistance to classical chemotherapy. CD20 down-modulation in response to microenvironmental stimuli might be a theoretical explanation for cell adhesion-mediated antibody resistance. This is supported by the observation that stimulating normal B cells by co-culture with CD40L-expressing fibroblasts results in rapid CD20 endocytosis and thus reduces the cell-surface levels of CD20. ${ }^{98}$ Additionally, Kawabata 
et al. observed in the Ramos cell line that TGF $\beta$ signaling led to SMAD2/3 binding directly to the MS4A1 transcription start site, resulting in CD20 repression. ${ }^{99}$ However, we and others have shown that in CLL, the chemokine CXCL12 (also known as SDF1) produced by stromal cells in immune niches induces CD20 expression, and that the intraclonal CLL cell subpopulation that recently exited the lymph nodes is characterized by high levels of CD20. ${ }^{34}$ This has an important consequence for the mechanism of rituximab's action since, in vivo, rituximab infusion leads to rapid and preferential elimination of this aggressive, proliferative CLL cell subpopulation. The remaining large proportion of CLL cells can survive the rituximab therapy because of relatively weak cell-surface levels of CD20, but these cells have a gene-expression profile of non-activated CLL cells, which are relatively less able to activate the BCR pathway, and do not proliferate. It remains unclear which molecular pathways provide CLL cells in the lymph node microenvironment with resistance to rituximab, despite having high levels of CD20. ${ }^{97}$ The resistance to rituximab in the microenvironment seems to be limited to rituximab-mediated apoptosis and CDC.

\section{Combinatorial therapy of novel drugs and anti-CD20 monoclonal antibodies}

For over a decade, scientists and clinicians have become accustomed to the empirical experience that adding rituximab to other therapies leads to increased therapeutic efficacy in B-cell malignancies. This also prompted studies for strategies to induce higher CD20 levels on the Bcell surface to potentially sensitize malignant cells to antiCD20 monoclonal antibodies (summarized in Table 2). Several of these "CD20 inducers" are being explored in preclinical or phase I/II clinical trials, including aurora kinase inhibitors, FOXO1 inhibitors, and chromatin modulators. For example, it has been shown that in lymphomas, the aurora kinase inhibitor alisertib can be safely and successfully used in combination with vincristine and rituximab (phase I/II trial). ${ }^{72}$ Nevertheless, none of the "CD20 inducers" has been prioritized for phase III trials yet (see Table 2). Combining the BTK inhibitor ibrutinib with rituximab was expected to increase the BTK inhibitor's clinical efficacy. This hypothesis was supported by the observation that CLL/lymphoma cells become more sensitive to apoptosis and anti-CD20 monoclonal antibodies when mobilized from immune niches (a typical effect of BCR inhibitors). ${ }^{96,97}$ However, results from a phase II study ${ }^{12}$ demonstrated no benefit from adding rituximab to ibrutinib. Recent studies have shown that CD20 levels are repressed during ibrutinib therapy and that ibrutinib affects cells responsible for effector mechanisms such as T/NK cells and macrophages. The reduction of CD20 levels by ibrutinib has a clear impact on rituximab-mediated CDC and apoptosis. However, CD20 is not completely lost, which still allows for anti-CD20 monoclonal antibodies to bind to cells. Skarzynski et al. ${ }^{100}$ also suggested that ibrutinib reduces complement inhibitor CD55 levels, which might partially counterbalance the effects of lower CD20, but it seems that in the sum of all effects, rituximab or ofatumumab efficacy decreases during ibrutinib therapy.

CD20 levels appear to play an essential role in CDC induced by rituximab, but they seem to be less relevant for ADCC. ${ }^{101}$ Unfortunately, ibrutinib also affects the functions of $\mathrm{T}$ cells and NK cells by inhibiting their BTK or a related ITK. BTK is critical for regulating the functions of NK cells as BTK-less NK cells have impaired cytotoxic activity ${ }^{102}$ ITK signals downstream of the T-cell receptor and is required to activate NK cells through FcyRIII. ${ }^{103}$ Inhibiting BTK or ITK impairs the cytotoxic functions of NK cells (degranulation, cytokine secretion) and ADCC mediated by type I and II anti-CD20 monoclonal antibodies. ${ }^{104,105}$ Thus ibrutinib may impair $\mathrm{T}$ - and NK-cell functions through either BTK or ITK, or both. ${ }^{104}$ It has also been suggested that phagocytosis by macrophages is affected by ibrutinib, but it is unclear if this is due to BTK inhibition in these cells or an off-target effect. ${ }^{104-106}$ Based on the results from the iLLUMINATE study, ${ }^{49}$ the Food and Drug Administration has already approved the combination of ibrutinib plus obinutuzum$a b$ for treatment-naïve patients with CLL (Table 2). However, the control arm of the study with chlorambucil plus obinutuzumab did not allow a conclusion on whether obinutuzumab provided a real benefit. Alternatively, sequential ibrutinib administration after the anti-CD20 monoclonal antibody could conceivably allow for better antibody effects. However, a clinical trial in CLL showed that sequential treatment with ofatumumab before ibrutinib was inferior to starting ibrutinib first, followed by the administration of ibrutinib and ofatumum$a b{ }^{107}$ Since obinutuzumab acts in part through mechanisms different from those of type I antibodies (rituximab, ofatumumab), its combination with ibrutinib may lead to different effects and increased clinical efficacy. Alternatively, other BTK inhibitors, such as acalabrutinib, are more selective with less off-target activity and likely do not interfere with antibody-dependent cellular phagocytosis or ADCC. ${ }^{108}$ It needs to be determined whether acalabrutinib is more suitable than ibrutinib for therapeutic combination with anti-CD20 monoclonal antibodies. Recently, a phase III study showed that acalabrutinib combined with obinutuzumab is highly efficient in prolonging progression-free survival when compared to obinutuzumab and chlorambucil in patients with previously untreated CLL. ${ }^{109}$

An interesting case is also the PI3K $\delta$ inhibitor idelalisib, which is currently approved for use in combination with rituximab to treat relapsed CLL based on a comparison to rituximab alone (Table 2). ${ }^{110}$ A similar phase III study showed that the progression-free survival of participants treated with a combination of idelalisib and ofatumumab was significantly longer than that of the group treated with ofatumumab only (Table 2) ${ }^{111}$ However, it is unclear whether adding rituximab or ofatumumab to idelalisib actually provides any clinical benefit, and based on the understanding of $\mathrm{CD} 20$ regulation, it is very likely that PI3K inhibitors also repress CD20 expression. In fact, data indicate that any inhibitor repressing Akt or NFKB or CXCR4 activity in B cells, such as a SYK inhibitor, BTK inhibitor, PI3K $\delta$ inhibitor, or CXCR4 antagonist, also reduces $\mathrm{CD} 20$ expression, leading to decreased binding of anti-CD20 monoclonal antibodies. ${ }^{44,70,100,112,113}$ Notably, SRC inhibitors such as dasatinib also repress CD20 transcription and impair NK cell functions. ${ }^{112}$ Additionally, PI3K $\delta$ plays a critical role in maturation, development, and effector functions of NK cells, which would indicate that it might impair ADCC. However, some studies indicate that this might be less prominent than ibrutinib's effects $^{114}$ or that idelalisib does not reduce ADCC at all. ${ }^{115}$ 
Idelalisib was also shown to decrease IFN $\gamma$ production by NK cells, and reduce secretion of various cytokines by $\mathrm{T}$ cells (IL6, IL10, TNF $\alpha$, and CD40L). ${ }^{115}$ More studies will be needed to determine whether other BTK or PI3K inhibitors have a better profile in terms of affecting ADCC/antibody-dependent cellular phagocytosis, but it seems inevitable that they will all lead to reduced levels of CD20.

The BH3-mimetic venetoclax was also tested in combination with anti-CD20 monoclonal antibodies. It seems that in contrast to "BCR inhibitors", there are no obvious biological reasons preventing an additive or synergistic effect of such a combination. The Food and Drug Administration granted approval for the use of venetoclax in combination with obinutuzumab for patients with previously untreated CLL/small lymphocytic lymphoma and in combination with rituximab to treat patients with CLL/ small lymphocytic lymphoma who have received at least one prior therapy (Table 2). ${ }^{116}$ The biological rationale for such combinations in CLL is provided, among others, by a study showing that combining venetoclax and anti-CD20 monoclonal antibodies overcomes microenvironment-mediated resistance of CLL cells to venetoclax monotherapy in vitro. ${ }^{117}$

\section{Conclusion}

Although CD20 is considered to be an ideal therapeutic target and rituximab-based immunotherapy has become a standard of care for a majority of B-cell malignancies, it is still unclear what all the functions of CD20 are, and how its expression is regulated. The main reason is the large heterogeneity of patients with B-cell malignancies and the lack of mouse models with an evident phenotype which makes CD20 analysis in vivo more difficult. A full understanding of the complexity of regulation of CD20, its physiological function and the exact mechanism of action of anti-CD20 monoclonal antibodies is of pivotal importance to develop new modified anti-CD20 monoclonal antibodies and their therapeutic combination that would yield better clinical efficacy and/or less toxicity. Recently, the possible role of CD20 in microenvironmental interactions was underscored by the observation that CD20 is upregulated in the context of immune niches. This is likely to be of physiological importance, especially for BCR signaling; however, it is unclear if this is related to the putative function of CD20 as a regulator of calcium flux triggered by BCR or any potential role in T-cell interactions or some additional function(s). Further investigation of the physiological function of CD20 is required, including the identification of molecules that interact with CD20, since this has implications for the development of rational therapeutic combinations and strategies.

\section{Acknowledgments}

Supported by the Ministry of Health of the Czech Republic, grant No. NU20-03-00292. All rights reserved. This project has received funding from the European Research Council (ERC) under the European Union's Horizon 2020 research and innovation programme (grant agreement n. 802644). Figures were created using BioRender graphical tool. We would like to thank Prof. Jiri Mayer, MD (University Hospital Brno) for inspiring discussions about anti-CD20 monoclonal antibodies.

\section{References}

1. Salles G, Barrett M, Foà R, et al. Rituximab in $B$-cell hematologic malignancies: a review of 20 years of clinical experience. Adv Ther. 2017;34(10):2232-2273.

2. Mössner E, Brünker $\mathrm{P}$, Moser S, et al. Increasing the efficacy of CD20 antibody therapy through the engineering of a new type II anti-CD20 antibody with enhanced direct and immune effector cell-mediated Bcell cytotoxicity. Blood. 2010;115(22):43934402.

3. Boross P, Leusen JHW. Mechanisms of action of CD20 antibodies. Am J Cancer Res. 2012;2(6):676-690.

4. Smith MR. Rituximab (monoclonal antiCD20 antibody): mechanisms of action and resistance. Oncogene. 2003;22(47):73597368.

5. Goede V, Fischer K, Busch R, et al. Obinutuzumab plus chlorambucil in patients with CLL and coexisting conditions. N Engl J Med. 2014;370(12):1101-1110.

6. Marcus R, Davies A, Ando K, et al. Obinutuzumab for the first-line treatment of follicular lymphoma. N Engl J Med. 2017;377(14):1331-1344

7. Hiddemann W, Barbui AM, Canales MA, et al. Immunochemotherapy with obinutuzumab or rituximab for previously untreated follicular lymphoma in the GALLIUM study: influence of chemotherapy on efficacy and safety. J Clin Oncol. 2018;36 (23):2395-2404.

8. Vitolo $U$, Trněný $M$, Belada $D$, et al. Obinutuzumab or rituximab plus cyclophosphamide, doxorubicin, vincristine, and prednisone in previously untreated diffuse large B-cell lymphoma. J Clin Oncol. 2017;35(31):3529-3537.

9. Burger JA, Keating MJ, Wierda WG, et al. Safety and activity of ibrutinib plus rituximab for patients with high-risk chronic lymphocytic leukaemia: a single-arm, phase 2 study. Lancet Oncol. 2014;15(10):10901099.

10. Seymour JF, Kipps TJ, Eichhorst B, et al. Venetoclax-rituximab in relapsed or refractory chronic lymphocytic leukemia. $\mathrm{N}$ Engl J Med. 2018;378(12):1107-1120.

11. Wang Y, Zhang W, Han Q, et al. Effective response and delayed toxicities of refractory advanced diffuse large B-cell lymphoma treated by CD20-directed chimeric antigen receptor-modified T cells. Clin Immunol. 2014;155(2):160-175.

12. Burger JA, Sivina $M$, Jain $N$, et al. Randomized trial of ibrutinib vs ibrutinib plus rituximab in patients with chronic lymphocytic leukemia. Blood. 2019;133(10): 1011-1019.

13. Tedder TF, Klejman G, Schlossman SF, Saito $\mathrm{H}$. Structure of the gene encoding the human B lymphocyte differentiation antigen CD20 (B1). J Immunol. 1989;142(7):25602568.
14. Eon Kuek L, Leffler M, Mackay GA, Hulett MD. The MS4A family: counting past 1,2 and 3. Immunol Cell Biol. 2016;94(1):11-23.

15. Henry C, Deschamps M, Rohrlich P-S, et al. Identification of an alternative CD20 transcript variant in B-cell malignancies coding for a novel protein associated to rituximab resistance. Blood. 2010;115(12):2420-2429.

16. Gamonet C, Bole-Richard E, Delherme A, et al. New CD20 alternative splice variants: molecular identification and differential expression within hematological B cell malignancies. Exp Hematol Oncol. 2016;5:7.

17. Tedder TF, Schlossman SF. Phosphorylation of the B1 (CD20) molecule by normal and malignant human B lymphocytes. J Biol Chem. 1988;263(20):10009-10015.

18. Zuccolo J, Deng L, Unruh TL, et al. Expression of MS4A and TMEM176 genes in human B lymphocytes. Front Immunol. 2013;4:195

19. Bubien JK, Zhou LJ, Bell PD, Frizzell RA, Tedder TF. Transfection of the CD20 cell surface molecule into ectopic cell types generates a $\mathrm{Ca} 2+$ conductance found constitutively in B lymphocytes. J Cell Biol. 1993;121(5):1121-1132.

20. Polyak MJ, Li H, Shariat N, Deans JP. CD20 homo-oligomers physically associate with the $\mathrm{B}$ cell antigen receptor. Dissociation upon receptor engagement and recruitment of phosphoproteins and calmodulin-binding proteins. J Biol Chem. 2008;283(27):1854518552. 
21. Levy S, Shoham T. Protein-protein interactions in the tetraspanin web. Physiology. 2005;20(4):218-224.

22. Szöllósi J, Horejsí V, Bene L, Angelisová P, Damjanovich S. Supramolecular complexes of MHC class I, MHC class II, CD20, and tetraspan molecules (CD53, CD81, and CD82) at the surface of a B cell line JY. J Immunol. 1996;157(7):2939-2946.

23. Léveillé C, AL-Daccak R, Mourad W. CD20 is physically and functionally coupled to MHC class II and CD40 on human B cell lines. Eur J Immunol. 1999;29(1):65-74.

24. Deans JP, Kalt L, Ledbetter JA, Schieven GL, Bolen JB, Johnson P. Association of 75/80$\mathrm{kDa}$ phosphoproteins and the tyrosine kinases Lyn, Fyn, and Lck with the B cell molecule CD20. Evidence against involvement of the cytoplasmic regions of CD20. J Biol Chem. 1995;270(38):22632-22638.

25. Manshouri T, Do K, Wang X, et al. Circulating CD20 is detectable in the plasma of patients with chronic lymphocytic leukemia and is of prognostic significance. Blood. 2003;101(7):2507-2513.

26. Schuh E, Berer K, Mulazzani M, et al. Features of human CD3+CD20+ T cells. J Immunol. 2016;197(4):1111-1117.

27. Prevodnik VK, Lavren ak J, Horvat M, Novakovi BJ. The predictive significance of CD20 expression in B-cell lymphomas. Diagn Pathol. 2011;6:33

28. Olejniczak SH, Stewart CC, Donohue K, Czuczman MS. A quantitative exploration of surface antigen expression in common Bcell malignancies using flow cytometry. Immunol Invest. 2006;35(1):93-114.

29. Fang C, Zhuang Y, Wang L, et al. High levels of CD20 expression predict good prognosis in chronic lymphocytic leukemia. Cancer Sci. 2013;104(8):996-1001.

30. Johnson NA, Boyle M, Bashashati A, et al. Diffuse large B-cell lymphoma: reduced CD20 expression is associated with an inferior survival. Blood. 2009;113(16):37733780.

31. Horvat M, Kloboves Prevodnik V, Lavrencak J, Jezersek Novakovic B. Predictive significance of the cut-off value of CD20 expression in patients with B-cell lymphoma. Oncol Rep. 2010;24(4):1101-1107.

32. Perz J, Topaly J, Fruehauf S, Hensel M, Ho $A D$. Level of CD 20-expression and efficacy of rituximab treatment in patients with resistant or relapsing B-cell prolymphocytic leukemia and B-cell chronic lymphocytic leukemia. Leuk Lymphoma. 2002;43(1):149151.

33. Hsi ED, Kopecky KJ, Appelbaum FR, et al. Prognostic significance of CD38 and CD20 expression as assessed by quantitative flow cytometry in chronic lymphocytic leukaemia. Br J Haematol. 2003;120(6):10171025.

34. Pavlasova G, Borsky M, Svobodova V, et al. Rituximab primarily targets an intra-clonal BCR signaling proficient CLL subpopulation characterized by high CD20 levels. Leukemia. 2018;32(9):2028-2031.

35. Kuijpers TW, Bende RJ, Baars PA, et al. CD20 deficiency in humans results in impaired $\mathrm{T}$ cell-independent antibody responses. J Clin Invest. 2010;120(1):214222.

36. Uchida J, Lee Y, Hasegawa M, et al. Mouse CD20 expression and function. Int Immunol. 2004;16(1):119-129.

37. O'Keefe TL, Williams GT, Davies SL, Neuberger MS. Mice carrying a CD20 gene disruption. Immunogenetics. 1998;48(2): 125-132.
38. Morsy DED, Sanyal R, Zaiss AK, Deo R, Muruve DA, Deans JP. Reduced T-dependent humoral immunity in CD20-deficient mice. J Immunol. 2013;191(6):3112-3118.

39. Petrie RJ, Deans JP. Colocalization of the B cell receptor and CD20 followed by activation-dependent dissociation in distinct lipid rafts. J Immunol. 2002;169(6):2886-2891.

40. Li H, Ayer LM, Lytton J, Deans JP. Storeoperated cation entry mediated by CD20 in membrane rafts. J Biol Chem. 2003;278 (43):42427-42434.

41. Franke A, Niederfellner GJ, Klein C, Burtscher $\mathrm{H}$. Antibodies against CD20 or Bcell receptor induce similar transcription patterns in human lymphoma cell lines. PLoS One. 2011;6(2):e16596.

42. Walshe CA, Beers SA, French RR, et al. Induction of cytosolic calcium flux by CD20 is dependent upon $\mathrm{B}$ cell antigen receptor signaling. J Biol Chem. 2008;283(25):1697116984.

43. Kheirallah S, Caron P, Gross E, et al. Rituximab inhibits B-cell receptor signaling. Blood. 2010;115(5):985-994.

44. Pavlasova G, Borsky M, Seda V, et al. Ibrutinib inhibits CD20 upregulation on CLL B cells mediated by the CXCR4/SDF-1 axis. Blood. 2016;128(12):1609-1613.

45. Venugopal P, Sivaraman S, Huang XK, Nayini J, Gregory SA, Preisler HD. Effects of cytokines on CD20 antigen expression on tumor cells from patients with chronic lymphocytic leukemia. Leuk Res. 2000;24(5): 411-415.

46. Sivaraman S, Venugopal P, Ranganathan R, et al. Effect of interferon-alpha on CD20 antigen expression of $\mathrm{B}$-cell chronic lymphocytic leukemia. Cytokines Cell Mol Ther. 2000;6(2):81-87.

47. Sivaraman S, Deshpande CG, Ranganathan $\mathrm{R}$, et al. Tumor necrosis factor modulates CD 20 expression on cells from chronic lymphocytic leukemia: a new role for TNF alpha? Microsc Res Tech. 2000;50(3):251257.

48. Seda V, Mraz M. B-cell receptor signalling and its crosstalk with other pathways in normal and malignant cells. Eur J Haematol. 2015;94(3):193-205

49. Moreno C, Greil R, Demirkan F, et al. Ibrutinib plus obinutuzumab versus chlorambucil plus obinutuzumab in first-line treatment of chronic lymphocytic leukaemia (iLLUMINATE): a multicentre, randomised, open-label, phase 3 trial. Lancet Oncol. 2019;20(1):43-56

50. Hörl S, Bánki Z, Huber G, et al. Reduction of complement factor $\mathrm{H}$ binding to CLL cells improves the induction of rituximab-mediated complement-dependent cytotoxicity. Leukemia. 2013;27(11):2200-2208.

51. Golay J, Lazzari M, Facchinetti V, et al. CD20 levels determine the in vitro susceptibility to rituximab and complement of B-cell chronic lymphocytic leukemia: further regulation by CD55 and CD59. Blood. 2001;98(12):3383-3389.

52. Ahlgrimm M, Pfreundschuh $M$, Kreuz $M$, Regitz E, Preuss K-D, Bittenbring J. The impact of Fc- $\gamma$ receptor polymorphisms in elderly patients with diffuse large B-cell lymphoma treated with CHOP with or without rituximab. Blood. 2011;118(17):4657-4662.

53. Kennedy AD, Beum PV, Solga MD, et al. Rituximab infusion promotes rapid complement depletion and acute CD20 loss in chronic lymphocytic leukemia. J Immunol. 2004:172(5):3280-3288.

54. Capuano C, Romanelli M, Pighi C, et al. Anti-CD20 Therapy acts via FcrRIIIA to diminish responsiveness of human natural killer cells. Cancer Res. 2015;75(19):40974108

55. Racila E, Link BK, Weng W-K, et al. A polymorphism in the complement component C1qA correlates with prolonged response following rituximab therapy of follicular lymphoma. Clin Cancer Res. 2008;14(20): 6697-6703.

56. Janas E, Priest R, Wilde JI, White JH, Malhotra R. Rituxan (anti-CD20 antibody)induced translocation of CD20 into lipid rafts is crucial for calcium influx and apoptosis. Clin Exp Immunol. 2005;139(3):439-446.

57. Tsai P-C, Hernandez-Ilizaliturri FJ, Bangia N, Olejniczak SH, Czuczman MS. Regulation of CD20 in rituximab-resistant cell lines and B-cell non-Hodgkin lymphoma. Clin Cancer Res. 2012;18(4):1039-1050.

58. Thévenin C, Lucas BP, Kozlow EJ, Kehrl JH Cell type- and stage-specific expression of the CD20/B1 antigen correlates with the activity of a diverged octamer DNA motif present in its promoter. J Biol Chem. 1993;268(8):5949-5956.

59. Himmelmann A, Riva A, Wilson GL, Lucas BP, Thevenin C, Kehrl JH. PU.1/Pip and basic helix loop helix zipper transcription factors interact with binding sites in the CD20 promoter to help confer lineage- and stage-specific expression of CD20 in B lymphocytes. Blood. 1997;90(10):3984-3995

60. Gstaiger M, Knoepfel L, Georgiev O, Schaffner W, Hovens CM. A B-cell coactivator of octamer-binding transcription factors. Nature. 1995;373(6512):360-362.

61. Nagy M. Chapuis B, Matthes T. Expression of transcription factors Pu.1, Spi-B, Blimp-1, BSAP and oct-2 in normal human plasma cells and in multiple myeloma cells. $\mathrm{Br}$ Haematol. 2002;116(2):429-435

62. Winiarska M, Nowis D, Bil J, et al. Prenyltransferases regulate CD20 protein levels and influence anti-CD20 monoclonal antibody-mediated activation of complement-dependent cytotoxicity. J Biol Chem. 2012;287(38):31983-31993.

63. Mankaï A, Bordron A, Renaudineau Y, et al Purine-rich box-1-mediated reduced expression of CD20 alters rituximab-induced lysis of chronic lymphocytic leukemia B cells. Cancer Res. 2008;68(18):7512-7519.

64. Wojciechowski W, Li H, Marshall S, Dell'Agnola C, Espinoza-Delgado I Enhanced expression of CD20 in human tumor B cells is controlled through ERKdependent mechanisms. J Immunol 2005;174(12):7859-7868.

65. Shimizu R, Kikuchi J, Wada T, Ozawa K, Kano Y, Furukawa Y. HDAC inhibitors augment cytotoxic activity of rituximab by upregulating CD20 expression on lymphoma cells. Leukemia. 2010;24(10):17601768 .

66. Hayashi K, Nagasaki E, Kan S, et al. Gemcitabine enhances rituximab-mediated complement-dependent cytotoxicity to $\mathrm{B}$ cell lymphoma by CD20 upregulation. Cancer Sci. 2016;107(5):682-689.

67. Seitz V, Butzhammer P, Hirsch B, et al. Deep sequencing of MYC DNA-binding sites in Burkitt lymphoma. PLoS One. 2011;6(11): e26837.

68. Filip D, Mraz M. The role of MYC in the transformation and aggressiveness of 'indolent' B-cell malignancies. Leuk Lymphoma. 2020;61(3):510-524

69. Słabicki M, Lee KS, Jethwa A, et al. Dissection of CD20 regulation in lymphoma using RNAi. Leukemia. 2016;30(12):2409 2412 
70. Pyrzynska B, Dwojak M, Zerrouqi A, et al. FOXO1 promotes resistance of nonHodgkin lymphomas to anti-CD20-based therapy. Oncoimmunology. 2018;7(5): e1423183.

71. Trinh DL, Scott DW, Morin RD, et al. Analysis of FOXO1 mutations in diffuse large B-cell lymphoma. Blood. 2013;121 (18):3666-3674

72. Kelly KR, Friedberg JW, Park SI, et al. Phase I study of the investigational Aurora A kinase inhibitor alisertib plus rituximab or rituximab/vincristine in relapsed/refractory aggressive B-cell lymphoma. Clin Cancer Res Off J Am Assoc Cancer Res. 2018:24(24):6150-6159.

73. Manfredi M. Combination of Aurora kinase inhibitors and anti-CD20 antibodies. US20100183601A1.

74. Tomita A, Hiraga J, Kiyoi H, et al. Epigenetic regulation of $\mathrm{CD} 20$ protein expression in a novel B-cell lymphoma cell line, RRBL1, established from a patient treated repeatedly with rituximab-containing chemotherapy. Int J Hematol. 2007;86(1):49-57.

75. Hiraga J, Tomita A, Sugimoto $\mathrm{T}$, et al. Down-regulation of $\mathrm{CD} 20$ expression in Bcell lymphoma cells after treatment with rituximab-containing combination chemotherapies: its prevalence and clinical significance. Blood. 2009:113(20):4885-4893.

76. Sugimoto T, Tomita A, Hiraga J, et al. Escape mechanisms from antibody therapy to lymphoma cells: downregulation of CD20 mRNA by recruitment of the HDAC complex and not by DNA methylation. Biochem Biophys Res Commun. 2009:390(1):48-53.

77. Tsutsumi Y, Ohigashi H, Ito S, Shiratori S, Teshima T. 5-Azacytidine partially restores CD20 expression in follicular lymphoma that lost CD20 expression after rituximab treatment: a case report. J Med Case Rep. 2016;10:27.

78. Damm JK, Gordon S, Ehinger M, et al. Pharmacologically relevant doses of valproate upregulate CD20 expression in three diffuse large B-cell lymphoma patients in vivo. Exp Hematol Oncol. 2015;4:4

79. Drott K, Hagberg H, Papworth K, Relander $\mathrm{T}$, Jerkeman $\mathrm{M}$. Valproate in combination with rituximab and $\mathrm{CHOP}$ as first-line therapy in diffuse large B-cell lymphoma (VALFRID). Blood Adv. 2018;2(12):1386-1392

80. Scialdone A, Hasni MS, Damm JK, Lennartsson A, Gullberg U, Drott K. The HDAC inhibitor valproate induces a bivalent status of the CD20 promoter in CLL patients suggesting distinct epigenetic regulation of CD20 expression in CLL in vivo. Oncotarget. 2017;8(23):37409-37422.

81. Frys S, Simons Z, Hu O, et al. Entinostat, a novel histone deacetylase inhibitor is active in B-cell lymphoma and enhances the antitumour activity of rituximab and chemotherapy agents. Br J Haematol. 2015;169(4):506-519.

82. Bobrowicz M. Dwojak M. Pyrzynska B, et al. HDAC6 inhibition upregulates CD20 levels and increases the efficacy of anti-CD20 monoclonal antibodies. Blood. 2017;130(14): 1628-1638

83. Gagez A-L, Duroux-Richard I, Leprêtre S, et al. miR-125b and miR-532-3p predict the efficiency of rituximab-mediated lymphodepletion in chronic lymphocytic leukemia patients. A French Innovative Leukemia Organization study. Haematologica. 2017;102 (4):746-754.

84. Williams ME, Densmore JJ, Pawluczkowycz AW, et al. Thrice-weekly low-dose rituximab decreases CD20 loss via shaving and promotes enhanced targeting in chronic lymphocytic leukemia. J Immunol. 2006;177 (10):7435-7443

85. Baig NA, Taylor RP, Lindorfer MA, et al Induced resistance to ofatumumab-mediated cell clearance mechanisms, including complement-dependent cytotoxicity, in chronic lymphocytic leukemia. J Immunol. 2014;192(4):1620-1629.

86. Beers SA, French RR, Chan HTC, et al. Antigenic modulation limits the efficacy of anti-CD20 antibodies: implications for antibody selection. Blood. 2010;115(25):51915201

87. Niederfellner G, Lammens A, Mundigl O, et al. Epitope characterization and crystal structure of GA101 provide insights into the molecular basis for type I/II distinction of CD20 antibodies. Blood. 2011;118(2):358367.

88. Deans JP, Robbins SM, Polyak MJ, Savage JA. Rapid redistribution of CD20 to a low density detergent-insoluble membrane compartment. J Biol Chem. 1998;273(1):344-348.

89. Chan HTC, Hughes D, French RR, et al. CD20-induced lymphoma cell death is independent of both caspases and its redistribution into triton X-100 insoluble membrane rafts. Cancer Res. 2003:63(17):5480-5489.

90. Lim SH, Vaughan AT, Ashton-Key M, et al. Fc gamma receptor IIb on target $B$ cells promotes rituximab internalization and reduces clinical efficacy. Blood. 2011;118(9):25302540 .

91. Johnson NA, Leach $S$, Woolcock B, et al CD20 mutations involving the rituximab epitope are rare in diffuse large B-cell lymphomas and are not a significant cause of RCHOP failure. Haematologica. 2009;94(3): 423-427.

92. Terui Y, Mishima Y, Sugimura N, et al. Identification of CD20 C-terminal deletion mutations associated with loss of CD20 expression in non-Hodgkin's lymphoma. Clin Cancer Res. 2009:15(7):2523-2530.

93. Nakamaki T, Fukuchi K, Nakashima H, et al. CD20 gene deletion causes a CD20-negative relapse in diffuse large B-cell lymphoma. Eur J Haematol. 2012;89(4):350-355

94. Stilgenbauer S, Schnaiter A, Paschka P, et al. Gene mutations and treatment outcome in chronic lymphocytic leukemia: results from the CLL8 trial. Blood. 2014;123(21):32473254

95. Pozzo F, Bittolo T, Arruga F, et al. NOTCH1 mutations associate with low CD20 level in chronic lymphocytic leukemia: evidence for a NOTCH1 mutation-driven epigenetic dysregulation. Leukemia. 2016;30(1):182-189.

96. Buchner M, Brantner P, Stickel N, et al. The microenvironment differentially impairs passive and active immunotherapy in chronic lymphocytic leukaemia - CXCR4 antagonists as potential adjuvants for monoclonal antibodies. Br J Haematol. 2010;151(2):167178.

97. Mraz M, Zent CS, Church AK, et al. Bone marrow stromal cells protect lymphoma Bcells from rituximab-induced apoptosis and targeting integrin alfa-4-beta-1 (VLA-4) with natalizumab can overcome this resistance. Br J Haematol. 2011;155(1):53-64.

98. Anolik J, Looney RJ, Bottaro A, Sanz I, Young F. Down-regulation of CD20 on B cells upon CD40 activation. Eur J Immunol. 2003;33(9):2398-2409.

99. Kawabata KC, Ehata S, Komuro A, Takeuch K, Miyazono K. TGF- -induced apoptosis of B-cell lymphoma Ramos cells through reduction of MS4A1/CD20. Oncogene. 2013;32(16):2096-2106

100. Skarzynski M, Niemann CU, Lee YS, et al. Interactions between ibrutinib and anti-
CD20 antibodies: competing effects on the outcome of combination therapy. Clin Cancer. 2016;22(1):86-95.

101. van Meerten $T$, van Rijn RS, Hol S, Hagenbeek A, Ebeling SB. Complementinduced cell death by rituximab depends on CD20 expression level and acts complementary to antibody-dependent cellular cytotoxicity. Clin Cancer Res. 2006;12(13):4027 4035.

102. Bao Y, Zheng J, Han C, et al. Correction Tyrosine kinase Btk is required for NK cell activation. J Biol Chem. 2020;295(10):3389.

103. Khurana D, Arneson LN, Schoon RA, Dick CJ, Leibson PJ. Differential regulation of human NK cell-mediated cytotoxicity by the tyrosine kinase Itk. J Immunol. 2007;178(6):3575-3582.

104. Da Roit F, Engelberts PJ, Taylor RP, et al Ibrutinib interferes with the cell-mediated anti-tumor activities of therapeutic CD2O antibodies: implications for combination therapy. Haematologica. 2015;100(1):77-86

105. Kohrt HE, Sagiv-Barfi I, Rafiq S, et al Ibrutinib antagonizes rituximab-dependent NK cell-mediated cytotoxicity. Blood. 2014;123(12):1957-1960.

106. Chu CC, Pinney JJ, VanDerMeid KR, et al. Anti-CD20 therapy reliance on antibody dependent cellular phagocytosis affects combination drug choice. Blood. 2019;134 (Supplement_1):682-682.

107. Jaglowski $\overline{S M}$, Jones JA, Nagar V, et al Safety and activity of BTK inhibitor ibrutinib combined with ofatumumab in chronic lymphocytic leukemia: a phase $1 \mathrm{~b} / 2$ study. Blood. 2015;126(7):842-850.

108. Golay J, Ubiali G, Introna M. The specific Bruton tyrosine kinase inhibitor acalabrutinib (ACP-196) shows favorable in vitro activity against chronic lymphocytic leukemia B cells with CD20 antibodies. Haematologica. 2017;102(10):e400-e403.

109. Sharman JP, Banerji V, Fogliatto LM, et al ELEVATE TN: Phase 3 study of acalabrutinib combined with obinutuzumab $(\mathrm{O})$ or alone vs o plus chlorambucil $(\mathrm{Clb})$ in patients (Pts) with treatment-naive chronic lymphocytic leukemia (CLL). Blood. 2019;134 (Suppl 1):31

110. Furman RR, Sharman JP, Coutre SE, et al Idelalisib and rituximab in relapsed chronic lymphocytic leukemia. N Engl J Med. 2014;370(11):997-1007.

111. Jones JA, Robak T, Brown JR, et al. Efficacy and safety of idelalisib in combination with ofatumumab for previously treated chronic lymphocytic leukaemia: an open-label, randomised phase 3 trial. Lancet Haematol. 2017;4(3):e114-e126.

112. Winiarska M, Bojarczuk K, Pyrzynska B, et al. Inhibitors of SRC kinases impair antitumor activity of anti-CD20 monoclonal antibodies. mAbs. 2014;6(5):1300-1313.

113. Bojarczuk K, Siernicka M, Dwojak M, et al B-cell receptor pathway inhibitors affect CD20 levels and impair antitumor activity of anti-CD20 monoclonal antibodies. Leukemia. 2014;28(5):1163-1167.

114. Guo H, Samarakoon A, Vanhaesebroeck B, Malarkannan S. The p110 delta of PI3K plays a critical role in NK cell terminal maturation and cytokine/chemokine generation. J Exp Med. 2008;205(10):2419-2435

115. Herman SEM, Gordon AL, Wagner AJ, et al. Phosphatidylinositol 3-kinase- $\delta$ inhibitor CAL-101 shows promising preclinical activity in chronic lymphocytic leukemia by antagonizing intrinsic and extrinsic cellular survival signals. Blood. 2010;116(12):2078 2088.

116. Fischer K, Al-Sawaf O, Bahlo J, et al. 
Venetoclax and obinutuzumab in patients with CLL and coexisting conditions. N Engl J Med. 2019;380(23):2225-2236.

117. Thijssen R, Slinger E, Weller $\mathrm{K}$, et al. Resistance to ABT-199 induced by microenvironmental signals in chronic lymphocytic leukemia can be counteracted by CD20 antibodies or kinase inhibitors. Haematologica. 2015;100(8):e302-e306.

118. Dimopoulos MA, Tedeschi A, Trotman J, et al. Phase 3 trial of ibrutinib plus rituximab in Waldenström's macroglobulinemia. N Engl J Med. 2018;378(25):2399-2410.

119. Woyach JA, Blachly JS, Rogers KA, et al. Acalabrutinib plus obinutuzumab in treat- ment-naïve and relapsed/refractory chronic lymphocytic leukemia. Cancer Discov. 2020;10(3):394-405

120. Mounier N, El Gnaoui T, Tilly $\mathrm{H}$, et al. Rituximab plus gemcitabine and oxaliplatin in patients with refractory/relapsed diffuse large B-cell lymphoma who are not candidates for high-dose therapy. A phase I Lymphoma Study Association trial Haematologica. 2013;98(11):1726-1731.

121. Mankaï A, Buhé V, Hammadi M, et al. Improvement of rituximab efficiency in chronic lymphocytic leukemia by CpGmediated upregulation of CD20 expression independently of PU.1. Ann N Y Acad Sci.
2009;1173:721-728

122. Friedberg JW, Kim H, McCauley M, et al Combination immunotherapy with a CpG oligonucleotide (1018 ISS) and rituximab in patients with non-Hodgkin lymphoma: increased interferon- $\alpha / \beta$-inducible gene expression, without significant toxicity. Blood. 2005;105(2):489-495.

123. Kozlova V, Ledererova A, Doubek M, Mayer J, Pospisilova S, Smida M. Epigenetic drug screen on resistant CLL cells reveals aurora kinase inhibitors as enhancers of CD20 expression and sensitizers to treatment with CD20 monoclonal antibodies. Blood. 2018;132(Suppl 1):4407. 